\section{(2) OPEN ACCESS}

\title{
Cardiac arrest during cornea transplant surgery
}

\author{
Allison Jarstad, ${ }^{1}$ Jody Chou, ${ }^{2}$ Sumit Garg ${ }^{3}$
}

${ }^{1}$ SoCal Eye Physicians in Long Beach, Long Beach, California, USA

${ }^{2}$ Anesthesiology and Perioperative Care, University of California Irvine School of Medicine, Orange, California, USA

${ }^{3}$ Ophthalmology, University of California Irvine School of Medicine, Irvine, California, USA

\section{Correspondence to}

Dr Sumit Garg;

gargs@hs.uci.edu

Accepted 31 July 2020

\section{Check for updates}

(c) BMJ Publishing Group Limited 2020. Re-use permitted under CC BY-NC. No commercial re-use. See rights and permissions. Published by BMJ.

To cite: Jarstad A Chou J, Garg S. BMJ Case Rep 2020;13:e235272. doi:10.1136/bcr-2020 235272

\section{SUMMARY}

This paper describes a case of cardiac arrest during femtosecond laser enabled penetrating keratoplasty (FLEK) in a young, healthy patient with no known cardiac risk factors and discusses the risk of cardiac arrest during intraocular surgery. A healthy 22 -year-old man who underwent repeat FLEK under general anaesthesia developed bradycardia and subsequent cardiac arrest while open sky during surgery. After resuscitation and completion of the transplant surgery, the patient recovered and the graft has survived with excellent uncorrected visual acuity over 1 year after surgery. Understanding the risks of cardiac arrest and death during intraocular surgery is imperative to discussing the systemic risks of surgery during the preoperative informed consent.

\section{BACKGROUND}

Intraoperative cardiac arrest is a dreaded complication of any surgery. In ophthalmology, the risk of cardiac arrest is extremely low, but is still a possibility. In this paper, we discuss a case of cardiac arrest during femtosecond laser enabled keratoplasty (FLEK) under general anaesthesia after the central cornea button had been removed, often referred to as 'open-sky'. It is imperative for ophthalmologists to be aware of the risks of general anaesthesia and to counsel patients of the rare but real risk of cardiac arrest and even death during eye surgery.

\section{CASE PRESENTATION}

The patient is a healthy 23-year-old man who underwent FLEK at the age of 17 in the left eye and at the age of 22 in the right eye for keratoconus (figure 1). Both surgeries were performed under general anaesthesia. The postoperative course in the left eye was uncomplicated; however, at 4 months following keratoplasty in the right eye, the patient experienced a rejection episode, treated with topical Pred Forte (Allergan, Irvine, California, USA) hourly for 1 week, which was then switched to topical Durezol (Alcon Laboratories, Fort Worth, Texas, USA) hourly for 2 weeks. The rejection episode resolved, but because of endothelial cell decompensation resulting in graft failure and visually significant corneal oedema, the decision was made to taper the Durezol and repeat right FLEK at postoperative month 6 .

For the first FLEK surgery on the right eye, the patient underwent an IntraLase iFS (Johnson and Johnson Vision, Santa Ana, California, USA) cut of his cornea in a zigzag-C pattern in the laser suite under topical anaesthesia without complication and was transferred to the operating room where general anaesthesia was initiated (table 1) and a laryngeal mask airway (LMA) was placed. A retrobulbar block was not given. After the surgical time out, the surgery lasted $51 \mathrm{~min}$ and the patient was extubated without complication.

The patient underwent his first keratoplasty at age 17 under general anaesthesia, so the surgeon decided to perform repeat FLEK in the right eye under general anaesthesia since this was the patient's third keratoplasty and the previous two surgeries proceeded without complication under general anaesthesia. Prior to surgery, the ECG revealed a normal sinus rhythm, the patient was pre-retreated with $2 \mathrm{mg}$ of midazolam and was taken to the operating theatre. After applying American Society of Anesthesia (ASA) standard monitors, general anaesthesia using an LMA was induced with $25 \mathrm{mcg}$ of fentanyl, $150 \mathrm{mg}$ of propofol and $100 \mathrm{mg}$ of lidocaine. The operating table was then turned 90 degrees counterclockwise, the patient was prepped and draped, a time out was performed and the surgery began. Again, a retrobulbar block was not given.

During the procedure, the previously placed donor corneal button was removed, and the fresh donor cornea was brought to the field. Three minutes into the surgery the first cardinal suture had been passed through the donor button but had not yet passed through the host cornea in the 12 o'clock meridian when the patient's heart rate became bradycardic, dropping from the 110's to the 20's. The surgeon was told to cease manipulation of the eye immediately. At that time there was no torquing of the eye away from primary position, but forceps had grasped the host cornea at the 12 o'clock position in preparation to pass the suture.

\section{INVESTIGATIONS}

The surgery was paused, $1 \mathrm{mg}$ of glycopyrrolate was given without any response of the heart rate, and the patient subsequently became asystolic without a pulse. Acute cardiac life support was initiated. Chest compressions were started immediately, a code was called and a crash cart was brought to the bedside. The surgeon took care to plug the open sky with a finger during chest compressions to prevent expulsion of intraocular contents. Defibrillator pads were placed, but no shock was given as the patient was still in asystole, so chest compressions were resumed. Epinephrine $1 \mathrm{mg}$ was given. Approximately $1 \mathrm{~min}$ after bradycardia was noted, the patient had return of a spontaneous heart rate with sinus tachycardia and a pulse was palpable. End 


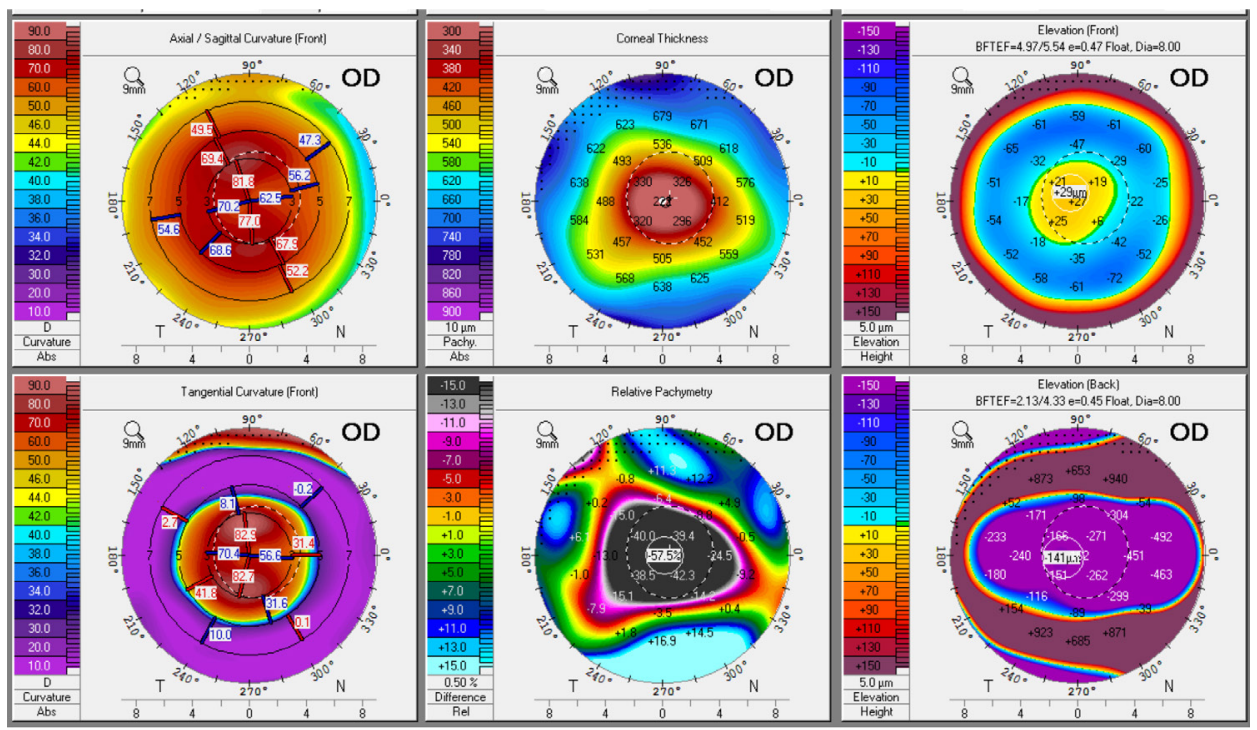

Figure 1 Oculus Pentacam topography for the right eye prior to the first femtosecond laser enabled keratoplasty revealing keratoconus with a central cone.

tidal carbon dioxide was in the 50's at this time. Three minutes later, the ECG showed a wide complex rhythm in the rate of 80 's. A $100 \mathrm{mg}$ bolus of lidocaine was given without a response, followed by $150 \mathrm{mg}$ of amiodarone, which resulted in resolution of the wide complex rhythm and return of sinus tachycardia. Next an arterial line was placed, and a point of care arterial blood gas (ABG) was drawn showing electrolyte abnormalities and an elevated glucose and creatinine (table 2). Systolic blood pressure was in the 70's after the arterial line was placed. Phenylephrine was given with improvement in blood pressure. The entire code lasted $5 \mathrm{~min}$, after which the surgical team proceeded with the remainder of the case.

\begin{tabular}{|c|c|c|c|}
\hline Medication & $\begin{array}{l}\text { First } \\
\text { anaesthesia } \\
\text { episode: } \\
\text { Left eye FLEK } \\
\# 1^{*}\end{array}$ & $\begin{array}{l}\text { Second } \\
\text { anaesthesia } \\
\text { episode: } \\
\text { Right eye } \\
\text { FLEK\#1 }\end{array}$ & $\begin{array}{l}\text { Third anaesthesia } \\
\text { episode: } \\
\text { Right eye FLEK \#2 }\end{array}$ \\
\hline Midazolam & $2 \mathrm{mg}$ & $2 \mathrm{mg}$ & $2 \mathrm{mg}$ \\
\hline Fentanyl & $25 \mu \mathrm{g}$ & $100 \mu g$ & $25 \mu \mathrm{g}$ \\
\hline Propofol & $200 \mathrm{mg}$ & $200 \mathrm{mg}$ & $150 \mathrm{mg}$ \\
\hline Lidocaine & $50 \mathrm{mg}$ & $100 \mathrm{mg}$ & $100 \mathrm{mg}, 100 \mathrm{mg} \dagger$ \\
\hline Dexamethasone & & $4 \mathrm{mg}$ & $4 \mathrm{mg}$ \\
\hline Ondansetron & $4 \mathrm{mg}$ & $4 \mathrm{mg}$ & $4 \mathrm{mg}$ \\
\hline Phenylephrine & $300 \mathrm{mg}$ & & \\
\hline Epinephrine & $20 \mathrm{mg}$ & & \\
\hline Glycopyrrolate & & & $1 \mathrm{mg}$ \\
\hline Epinephrine & & & $1 \mathrm{mg}$ \\
\hline Amiodarone & & & $150 \mathrm{mg}$ \\
\hline Calcium chloride & & & $1000 \mathrm{mg}$ \\
\hline $\begin{array}{l}\text { Lactated ringer's } \\
\text { solution }\end{array}$ & $800 \mathrm{~mL}$ & $800 \mathrm{~mL}$ & $800 \mathrm{~mL}$ \\
\hline
\end{tabular}

*The first anaesthesia episode is not described in detail in this paper.

tThe first bolus of lidocaine was given on initiation of anaesthesia and a second bolus of lidocaine was given during cardiac arrest.

FLEK, femtosecond laser enabled keratoplasty.

\section{OUTCOME AND FOLLOW-UP}

The new donor button had remained on the field during chest compressions and was found in the superior fornix under the eyelid. The donor button was sutured to the host quickly with 16 interrupted 10-0 nylon sutures. The knots were buried, and the graft host junction was confirmed to be Seidel negative prior to injecting subconjunctival cefazolin and methylprednisolone. The surgery lasted $43 \mathrm{~min}$ from initial incision to close, and paramedics were waiting outside the operating theatre when the surgery was complete. The patient was extubated and found to be awake, alert and following commands. A sign-out was given to the paramedics, who accompanied the patient to the recovery area, where the patient's heart rate was sinus tachycardia in the 120 's and blood pressure was 170/70 mm Hg.

The paramedics transferred the patient to a nearby hospital where he was admitted for cardiac testing. He was discharged 5 days later after his cardiac work-up was negative and electrolyte abnormalities resolved. The patient is currently doing well without systemic ramifications of the cardiac arrest episode. $\mathrm{He}$ experienced a second rejection episode of the right cornea while on topical prednisolone four times daily, which was treated with topical Durezol (Alcon Laboratories) every 2 hours and Combigan (Allergan, Madison, New Jersey, USA) twice daily to prevent intraocular pressure elevation. The keratoplasty graft

\begin{tabular}{lll}
\hline Table 2 & Intraoperative point of care limited arterial blood gas \\
\hline & Patient's reading & Normal \\
\hline Sodium & $136 \mathrm{mmol} / \mathrm{L}$ & $138-146 \mathrm{mEq} / \mathrm{L}$ \\
\hline Potassium & $4.00 \mathrm{mmol} / \mathrm{L}$ & $3.7-5.5 \mathrm{mmol} / \mathrm{L}$ \\
\hline Chloride & $99 \mathrm{mmo} / \mathrm{L}$ & $99-111 \mathrm{mmol} / \mathrm{L}$ \\
\hline Total $\mathrm{CO}_{2}$ & $21 \mathrm{mmo} / \mathrm{L}$ & $23-29 \mathrm{mmol} / \mathrm{L}$ \\
\hline Anion gap & $21 \mathrm{mmol} / \mathrm{L}$ & $10-20 \mathrm{mmol} / \mathrm{L}$ \\
\hline Glucose & $147 \mathrm{mg} / \mathrm{dL}$ & $70-110 \mathrm{mg} / \mathrm{dL}$ \\
\hline Blood urea nitrogen & $12 \mathrm{mg} / \mathrm{dL}$ & $7-25 \mathrm{mg} / \mathrm{dL}$ \\
\hline Creatinine & $2.5 \mathrm{mg} / \mathrm{dL}$ & $0.6-1.3 \mathrm{mg} / \mathrm{dL}$ \\
\hline Calcium ionised & $0.96 \mathrm{mmol} / \mathrm{L}$ & $1.13-1.32 \mathrm{mmol} / \mathrm{L}$ \\
\hline
\end{tabular}

Jarstad A, et al. BMJ Case Rep 2020;13:e235272. doi:10.1136/bcr-2020-235272 
is currently clear and the most recent uncorrected visual acuity over 1 year following repeat FLEK was 20/30. Vision in the left eye (which also underwent FLEK) remains 20/20 on Lotemax (Basuch and Lomb, Rochester, New York, USA) once daily. He has established care with cardiology and a repeat cardiac stress test was normal.

\section{DISCUSSION}

To the best of our knowledge this is the first reported case of intraoperative cardiac arrest during FLEK. Despite eye surgery being relatively 'safe' with low systemic risk, any surgery that involves anaesthesia carries the additional risks of cardiac arrest and death. Even if the risk is minimal, as surgeons, we are obligated to inform patients of the potential systemic adverse effects of surgery, not just those limited to the eye.

Cardiac arrest is a rare complication of surgery and anaesthesia. A Japanese study from 2004 reported the rate of cardiac arrest as 6.34 per 10000 anaesthesia cases. In the same study, the incidence of cardiac arrest totally attributed to anaesthetic mismanagement was only 0.47 per 10000 cases. $^{1}$ More commonly, cardiac arrest is due to preoperative health complications and intraoperative events such as surgical blood loss leading to haemorrhagic shock. The American College of Surgeons National Surgical Quality Improvement Database from 2005 to 2007 reports the incidence of cardiac arrest during noncardiac surgery as 7.22 per 10000 cases. In these cases, intraoperative blood loss was the most important risk factor for cardiac arrest. ${ }^{2}$ The risk increases with age as well as ASA physical status ranking, with the majority of arrests occurring in patients with an ASA physical status of 3, 4 or 5 (on a scale of $1-5$ ). ${ }^{3}$ Special situations that carry an increased risk of cardiac arrest include emergency surgery (163 per 10000 cases) and surgeries in children less than 1 year of age (22.9 per 10000 cases). ${ }^{45}$ Given the low levels of blood loss and that most intraocular surgeries are planned, the risks of cardiac arrest during intraocular surgery are extremely rare.

Rates of cardiac arrest during intraocular surgery are not well published. In the 1960's Petrusack, Smith and Breslin reviewed thousands of cases over a 10-year period at the Eye and Ear Hospital in Pittsburgh. After reviewing over 30000 anaesthesia cases, the study found only two deaths that occurred intraoperatively, both under local anaesthesia, not general. The death rate following general anaesthesia was 6.9 per 10000 cases and 3.5 per 10000 cases following local anaesthetic. ${ }^{6}$ The fact that no deaths occurred intraoperatively during eye surgery is especially remarkable, considering a 2013 study that analysed when perioperative cardiac arrest takes place. In this study of 2524 perioperative deaths from cardiac arrest within 24 hours of surgery, a stunning 1458 occurred intraoperatively. ${ }^{7}$

The oculocardiac reflex leading to bradycardia has been well established and is associated with manipulation of the globe, pressure on the orbital contents, a pulling force on the intraocular muscles and intravitreal injections. ${ }^{89}$ In this case, the patient's eye was in primary position when he became bradycardic and later asystolic, so it is possible, but unlikely, that this arrhythmia was a reflexive response to globe manipulation. In both surgeries on the right eye, a retrobulbar block was not performed. It is unclear if the presence of retrobulbar anaesthetic would have altered the outcome of the surgery, but this is an area in need of further investigation. Though some surgeons perform a retrobulbar, peribulbar or sub-Tenon's injection of anaesthetic at the time of keratoplasty surgery, we generally prefer to avoid injections into the orbital septum to minimise posterior pressure during open sky procedures to avoid expulsion of the intraocular contents while the cornea button is removed. Cornea transplant surgery does not involve the uvea which tends to be more painful, as such the authors do not routinely perform retrobulbar blocks in the setting of keratoplasty when general anaesthesia is used, however, this should be considered on a case-by-case basis.

In predisposed patients, slight changes in pressure on the globe and even changes in temperature of the eye can induce bradycardia. This is known as the diving reflex, which manifests as bradycardia when irrigation fluid of $20^{\circ} \mathrm{C}$ or cooler is applied along the ophthalmic division of the fifth cranial nerve. ${ }^{10}$ The bradycardia occurs without hypotension and can be more profound than that seen from the oculocardiac reflex. ${ }^{11}$ In the presented case, room temperature balanced salt solution was used to irrigate the ocular surface, but the eye was not irrigated at the time of the onset of the patient's bradycardia and is unlikely to have triggered the oculocardiac reflex in this case.

It is not clear why the patient experienced cardiac arrest. He may be vagotonic at baseline and susceptible, but his postoperative cardiac work-up has been negative. He had no known preoperative risk factors, and he had undergone uncomplicated general anaesthesia on two previous occasions for similar eye surgeries. Despite no comorbidities, his ASA score was 2 due to the previous two keratoplasties, and he had the same anaesthesiologist for both surgeries on the right eye (initial FLEK and repeat FLEK). The medications administered during anaesthesia induction were similar between cases on the right eye, with the exception of less fentanyl and propofol given in the third anaesthesia event (repeat FLEK of the right eye).

The limited point of care ABG (table 2) shows a sodium level of 136 , which does not meet the criteria for hyponatraemia and is clinically inconsequential. A mildly low bicarbonate level suggests mild metabolic acidosis which is common during cardiac arrest due to the increase of lactic acid. Unfortunately, a $\mathrm{pH}$ is not included in the point of care ABG that was done. Elevated glucose is likely a stress response related to the cardiac arrest or due to the bolus of epinephrine given during the resuscitation process. The patient's ionised calcium level was 0.96 , which was borderline low (normal range 1.13-1.32). This cause of mild hypocalcaemia is unclear although the patient did have an abnormal elevation of creatinine demonstrating possible chronic renal pathology. Chronic kidney disease can affect calcium levels through impaired vitamin D metabolism. Calcium is known to increase cardiac contractility, and when administered at a fast rate, a transient increase in heart rate can also be observed. However, calcium is not part of the recommended medications for symptomatic bradycardia, and this would not have been the initial drug of choice when the patient was first noted to have severe bradycardia. After the patient had return of spontaneous rhythm and regained a pulse, the point of care $A B G$ was drawn showing mildly low calcium. At this time calcium was not given because the patient had adequate blood pressure and heart rate; however, if the patient had been hypotensive with a mildly low calcium, administration of calcium could have been considered.

Although the final outcome was positive and the patient did not suffer from permanent systemic effects, not all surgical teams are as fortunate when faced with this devastating intraoperative event.

One may easily overlook mentioning the risk of intraoperative cardiac arrest and death during the preoperative informed consent, given that the rate is low. However, we urge ophthalmologists to include this in preoperative discussion, given that the risk exists and the outcomes of cardiac arrest can be devastating and significant. 


\section{Learning points}

- Cardiac arrest, though rare, is a well-document risk of any ocular surgery.

- It is imperative for ophthalmologists to counsel their patients on this risk during preoperative discussions prior to surgery.

- When cardiac arrest occurs, prompt implementation of advanced cardiac life support with a cohesive team approach can lead to successful resuscitation.

- During open sky procedures, it is imperative to plug the wound during chest compressions to prevent expulsion of intraocular contents.

Contributors AJ, JC and SG contributed equally to this case report.

Funding The authors have not declared a specific grant for this research from any funding agency in the public, commercial or not-for-profit sectors.

Competing interests None declared.

\section{Patient consent for publication Obtained.}

Provenance and peer review Not commissioned; externally peer reviewed.

Open access This is an open access article distributed in accordance with the Creative Commons Attribution Non Commercial (CC BY-NC 4.0) license, which permits others to distribute, remix, adapt, build upon this work non-commercially, and license their derivative works on different terms, provided the original work is properly cited and the use is non-commercial. See: http://creativecommons.org/ licenses/by-nc/4.0/.

\section{REFERENCES}

1 Irita K, Kawashima Y, Iwao Y, et al. [Annual mortality and morbidity in operating rooms during 2002 and summary of morbidity and mortality between 1999 and 2002 in Japan: a brief review]. Masui 2004;53:320-35.

2 Goswami S, Brady JE, Jordan DA, et al. Intraoperative cardiac arrests in adults undergoing noncardiac surgery: incidence, risk factors, and survival outcome. Anesthesiology 2012;117:1018-26.

3 Nunnally ME, O'Connor MF, Kordylewski $\mathrm{H}$, et al. The incidence and risk factors for perioperative cardiac arrest observed in the National anesthesia clinical outcomes registry. Anesth Analg 2015;120:364-70.

4 Siriphuwanun V, Punjasawadwong Y, Lapisatepun W, et al. Incidence of and factors associated with perioperative cardiac arrest within 24 hours of anesthesia for emergency surgery. Risk Manag Healthc Policy 2014;7:155-62.

5 Gobbo Braz Let al. Perioperative cardiac arrest and its mortality in children. A 9-year survey in a Brazilian tertiary teaching hospital. Paediatr Anaesth 2006;8:860-6.

6 Petruscak J, Smith RB, Breslin P. Mortality related to Ophthalmological surgery. Arch Ophthalmol 1973;89:106-9.

7 Ramachandran SK, Mhyre J, Kheterpal S, et al. American Heart Association's Get With The Guidelines-Resuscitation Investigators. Predictors of survival from perioperative cardiopulmonary arrests: a retrospective analysis of 2,524 events from the Get With The Guidelines-Resuscitation registry. Anesthesiology 2013;12:1322-39.

8 Van Brocklin MD, Hirons RR, Yolton RL. The oculocardiac reflex: a review. J Am Optom Assoc 1982;53:407-13

9 Paciuc-Beja M, Meizner-Grezemkovsky D, Paciuc M, et al. Oculocardiac reflex during intravitreal injection. Med Hypothesis Discov Innov Ophthalmol 2020;9:111-7.

10 Arndt GA, Stock MC. Bradycardia during cold ocular irrigation under general anaesthesia: an example of the diving reflex. Can J Anaesth 1993;40:511-4.

11 Berk WA, Shea MJ, Crevey BJ. Bradycardic responses to vagally mediated bedside maneuvers in healthy volunteers. Am J Med 1991;90:725-9.

Copyright 2020 BMJ Publishing Group. All rights reserved. For permission to reuse any of this content visit

https://www.bmj.com/company/products-services/rights-and-licensing/permissions/

BMJ Case Report Fellows may re-use this article for personal use and teaching without any further permission.

Become a Fellow of BMJ Case Reports today and you can:

- Submit as many cases as you like

- Enjoy fast sympathetic peer review and rapid publication of accepted articles

- Access all the published articles

- Re-use any of the published material for personal use and teaching without further permission

Customer Service

If you have any further queries about your subscription, please contact our customer services team on +44 (0) 2071111105 or via email at support@bmj.com.

Visit casereports.bmj.com for more articles like this and to become a Fellow 